\title{
Que novas há do mundo lá fora?
}

\section{Francesca Rayner}

\footnotetext{
Medida por medida,

de W. Shakespeare,

enc. Nuno Cardoso,

Ao Cabo Teatro,

Guimarães 2012 - Capital

Europeia da Cultura,

SLTM / TNSJ, 2012

(Pedro Frias

e Catarina Lacerda),

fot. João Tuna.
}

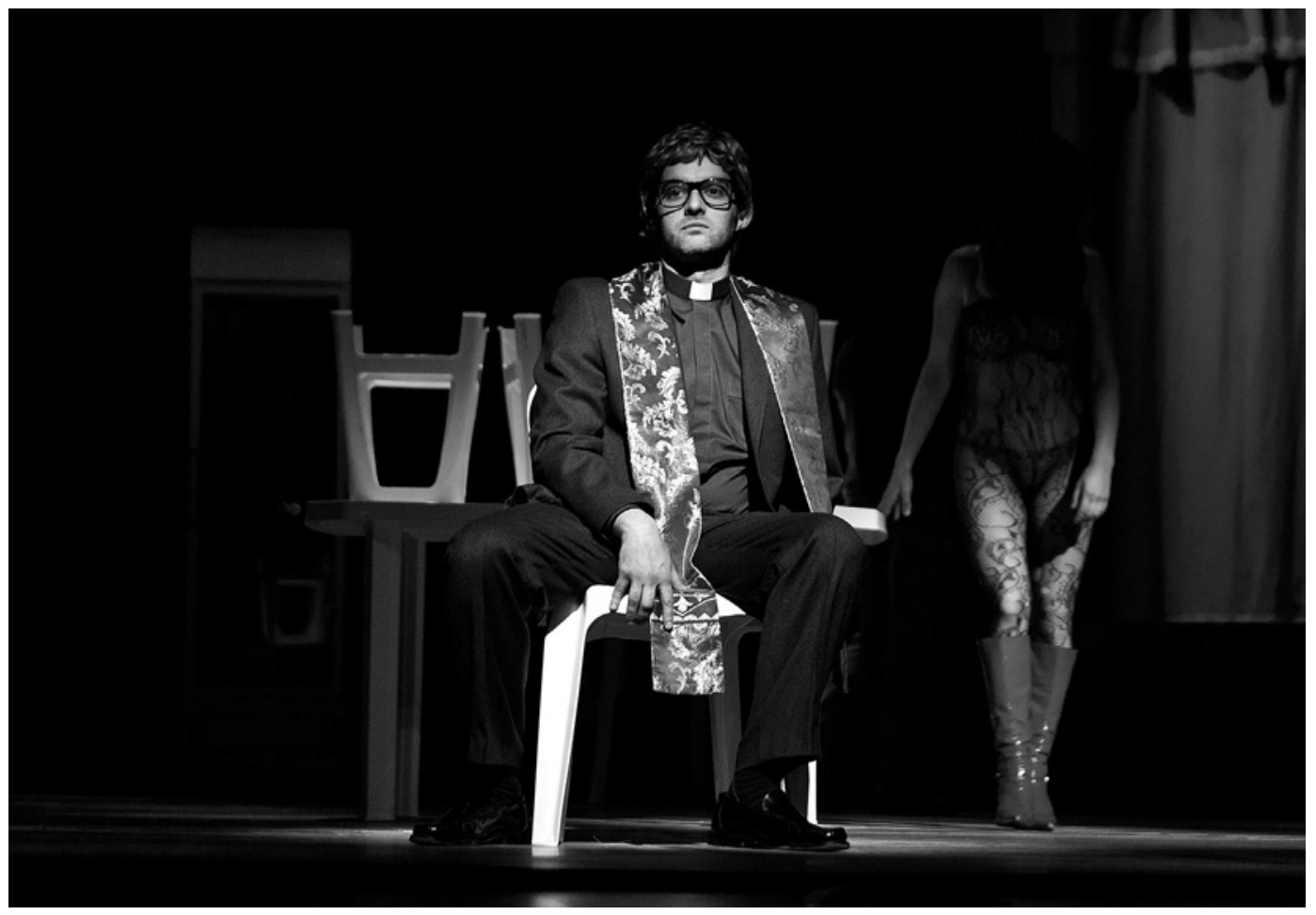

Titulo: Medida por medida (1604). Autor: William Shakespeare. Tradução: Fernando Villas Boas. Cenografia: F. Ribeiro. Encenação: Nuno Cardoso. Desenho de luz: José Álvaro Correia. Música original: Rui Lima e Sérgio Martins. Figurinos (consultor): Fernando Nunes. Assistência de encenação e movimento: Vitor Hugo Pontes. Interpretação: Afonso Santos (Puido, Bernardino, Fidalgo, Frade), Catarina Lacerda (Madame Bem-Passada, Mariana, Julieta), Cláudio da Silva (Angelo), Daniel Pinto (Lúcio), João Melo (Pompeu), Luís Araújo (Éscalo), Paulo Calatré (Meirinho, Fidalgo), Pedro Frias (Duque), Romeu Costa (Claúdio), Sara Carinhas (Isabela). Co-produção: Ao Cabo Teatro, Guimarães 2012 - Capital Europeia da Cultura, São Luiz Teatro Municipal, Teatro Nacional S. João. Local e data de estreia: Centro Cultural Vila Flor, Guimarães, 28 de Abril de 2012.

Depois de uma estreia algo hesitante e confusa em Guimarães no final de Abril, Medida por medida, pelo Ao Cabo Teatro, evoluiu de forma significativa até à sua apresentação no Teatro Nacional S. João no princípio de Maio. As complicações de um enredo potencialmente confuso - em que cabeças e corpos passam por objectos de troca e o registo dramático passa abruptamente de questões abstractas da lei e da religião para as realidades físicas da morte e da doença - tinham sido entretanto trabalhadas no sentido de permitirem uma leitura clara da peça: enquanto o que inicialmente parecia ser uma série de fragmentos improvisados, tinha-se juntado numa encenação mais coerente da peça.

Por razões várias é difícil pensar numa peça de Shakespeare que seja mais apropriada do que Medida por medida para se representar nestes tempos de austeridade e crise. De facto, as duas encenações anteriores da peça em Portugal (numa produção TAS / CCE em 1977 e da

Comuna em 1977) visavam explorar questões de política contemporânea e ocorreram também num tempo em que a relação entre o Estado e o teatro era um assunto preocupante. Uma peça que trata da corrupção - que é simultaneamente política e moral -, que desmistifica a arbitrariedade da lei e ilustra a substituição do argumento racional pela força fisica quando os homens têm um poder inexcedivel sobre as mulheres, pode ser visto como um veículo perfeito para a exploração do universo social em que este espectáculo se realiza.

Todavia, enquanto um público contemporâneo pode facilmente simpatizar com uma personagem como Cláudio (Romeu Costa) que está prestes a ser executado por terpraticado o sexo pré-marital de comum acordo, é mais 


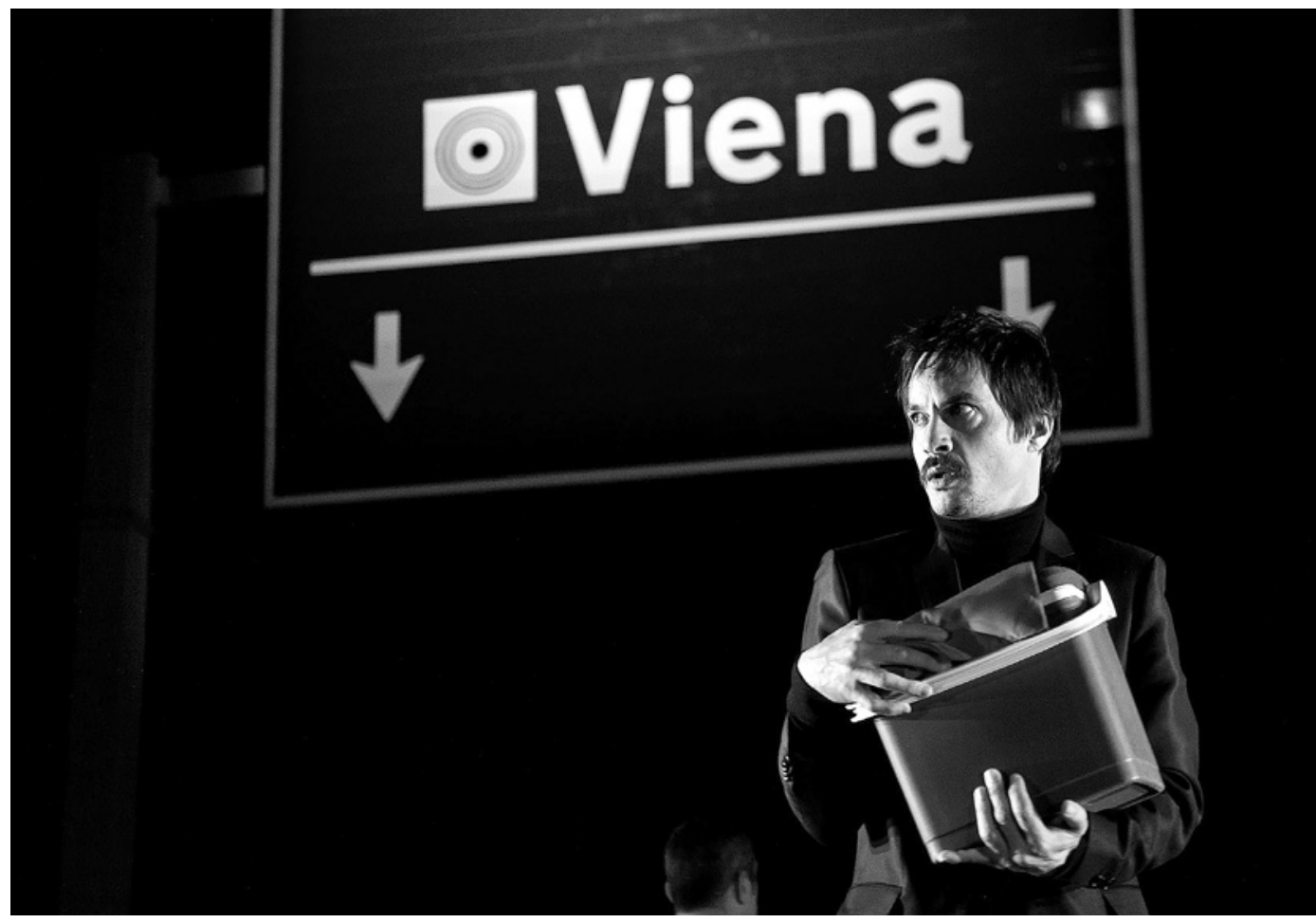

Medida por medida, de W. Shakespeare enc. Nuno Cardoso Ao Cabo Teatro, Guimarães 2012 - Capital Europeia da Cultura, SLTM / TNSJ, 2012 (Cláudio da Silva), fot. João Tuna.

dificil simpatizar com o dilema de uma possível futura freira (Isabel, Sara Carinhas) que preza a sua castidade acima da vida do seu irmão. É possível apresentar uma visão mais contemporânea de Isabel como protegendo a sua integridade física do que parece ser uma violação permitida "por lei", mas a decisão, que o encenador adoptou, ao vestir Isabela no que parecia um uniforme escolar. tendeu a fazer prevalecer a titilação sexual sobre o que poderia ser um reconhecimento de opressão sexual.

0 espectáculo trabalhou de forma mais bem-sucedida com as cenas de comédia - geralmente mal compreendidas - através de um recurso inteligente ao cómico mais físico do que verbal, e o ênfase ao longo do espectáculo na corporalidade seminua não apenas sublinhava a energia do corpo sexualmente anárquico que transgride os preceitos da repressão, mas também a sua fragilidade quando os regimes usam a tortura do corpo como uma arma política. As cenas da prisão, onde corpos perdidos, encapuzados, grávidos até circulavam sem rumo ou por ali ficavam expostos à vista do público, foram particularmente sugestivos remetendo para a imagem dos prisioneiros escondidos de Guantánamo e Abu Ghraib. Ou para prisões mais perto de nós, em que o tratamento dado aos prisioneiros raras vezes se torna visivel fora da própria prisão.
A acção da peça ocorre numa espécie de espaço indefinido que caracteriza a cultura contemporânea, com mudanças de cena indicadas apenas pelas reconfigurações da mesa e das cadeiras. Funcionou como em espaço de palco económico e multifacetado para as prostitutas, chulos e seus clientes se relacionarem com o Duque (Pedro Frias) e com outras figuras de autoridade, enquanto a única possibilidade de escapar deste espaço era proporcionada, de forma algo irónica, por um pequeno palco com cortina, num dos lados do palco. Este palco pequenino (um emblema do futuro limitado do teatro subsidiado em Portugal?) permitia que eventos diferentes se representassem simultaneamente. Por exemplo, Mariana (Catarina Lacerda) tinha o seu encontro privado com Ângelo enquanto o Duque tentava reformar Viena em palco. 0 palco podia ainda lembrar ao público o que estava em causa nos momentos dramáticos mais importantes, como quando um Cláudio seminu se agachava desconfortavelmente numa cadeira enquanto a sua irmã intercedia pela vida dele junto de Ângelo (Cláudio da Silva) no palco principal. 0 palco com cortina era o único espaço privado em cena, mas no último acto o Duque reaparecia aí como um líder político renascido numa mudança de regime efectuada entre simbólicas bandeiras cor de laranja agitadas por apoiantes 

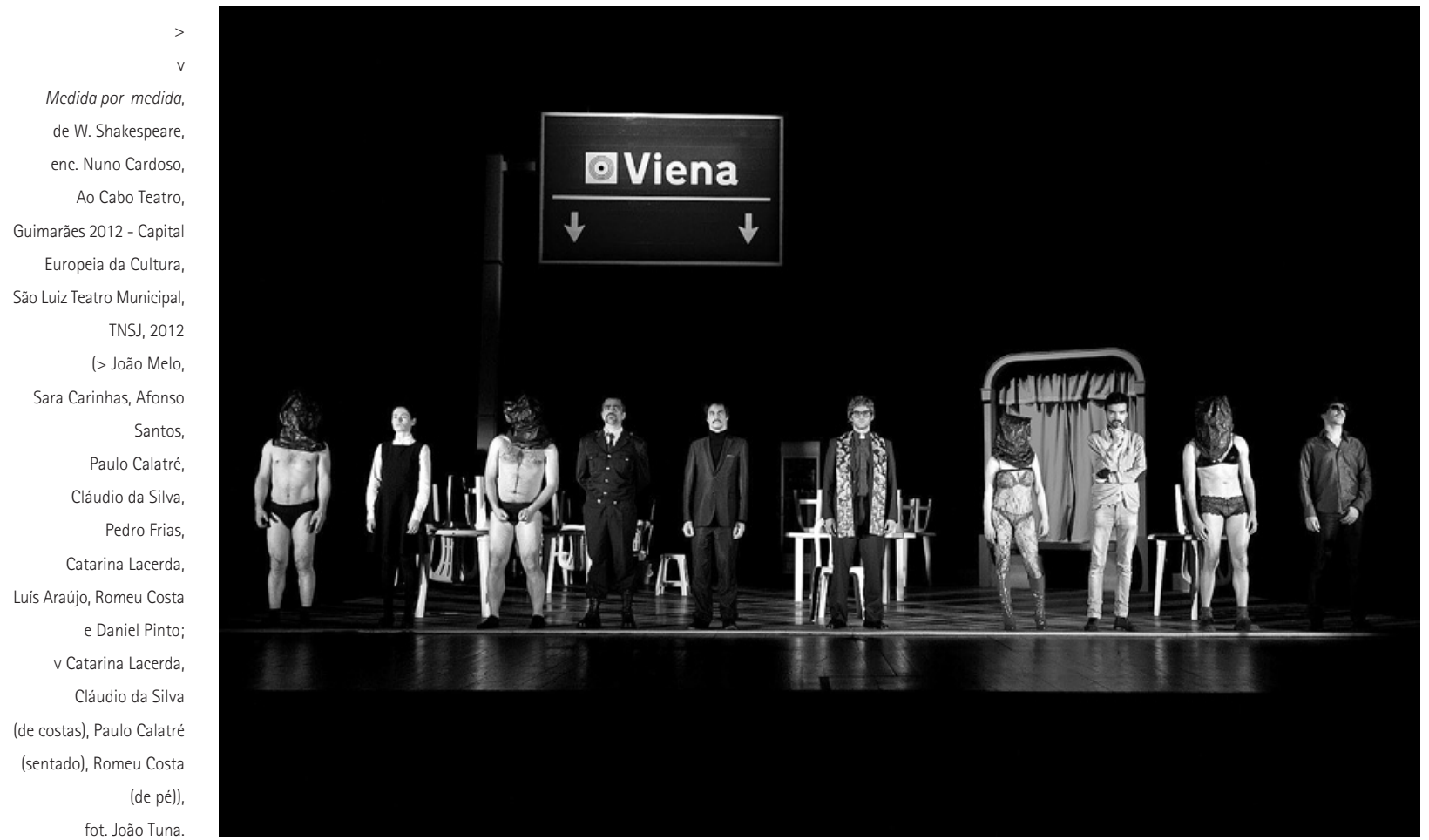

entusiastas.

Com um sinal rodoviário acima do palco que apontava as setas na direcção de Viena - referindo-se ao palco em baixo - o espectáculo equilibrava bem a necessidade de contar a história com um desejo de sublinhar o seu conteúdo político. A dona do bordel Madame Bem-Passada (Catarina Lacerda), por exemplo, anotava na sua lista os factores negativos que afectavam o seu comércio, como a guerra, a fome, ou a "austeridade", e julgo ter ouvido que a fuga do Duque para a Polónia tinha passado a ser uma fuga para a Alemanha. 0 espectáculo sublinhava como, no vazio criado pelo fracasso da liderança política do Duque, são as personagens amorais, adaptáveis e vivaças como Lúcio (interpretado de forma soberba por Daniel Pinto) que sobrevivem e prosperam, enquanto os que falam a verdade, ou ninguém acredita no que dizem ou são ameaçados de prisão por difamarem o Estado.

A relação entre o texto dramático e o contexto socia surgia de forma relativamente harmoniosa o que se deveu tanto ao encenador (Nuno Cardoso) como aos actores, que se movimentavam com grande destreza pelos espaços da cena em interpretações que conferiam um ritmo rápido ao espectáculo no seu todo. Isso também resultava dos cortes judiciosos da tradução - apurada e ágil - de Fernando Villas-Boas e do interesse da própria história. A encenação permitia momentos de virtuosismo individual, como quando Mariana entoava uma canção langorosa ou Bernardino (Afonso Santos), bêbado, se recusava obstinadamente, perante o Duque, a ser executado, ao mesmo tempo que mantinha uma atenção ao conjunto que, com excepção de umas poucas palavras, que se perdem, e, aqui e ali, uma falta de variedade no discurso falado, todos tiveram boas interpretações. Merece menção especial Sara Carinhas pela inteligência com que interpretou o papel de Isabela. Para terminar com um exemplo que a envolvia muito particularmente: em Guimarães fiquei horrorizada no fim do espectáculo quando, em resposta

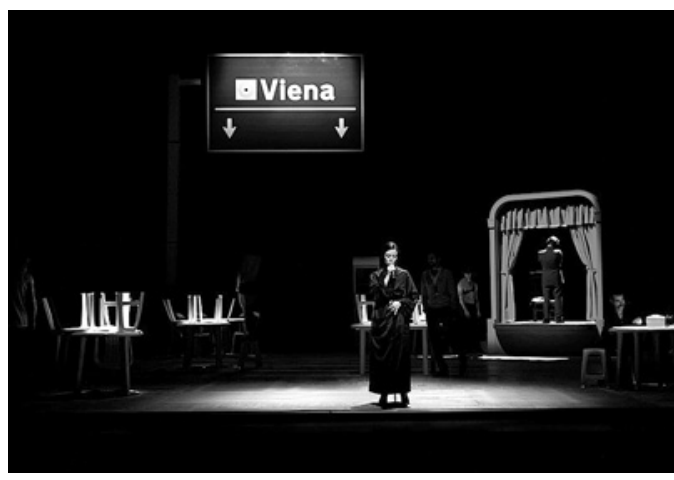

à proposta de casamento do Duque, a actriz simplesmente enrolou o vestido de noiva à sua volta, sugerindo uma improvável libertação sexual através do casamento a uma figura que Ihe mentiu consistentemente. Contudo, quando o espectáculo chegou ao Porto, o vestido de casamento era atirado com desprezo do palco para a sala, em baixo enquanto a actriz saía resolutamente de cena. Este pareceume um final muito mais apropriado para uma peça que dificilmente pode ser considerada como uma comédia romântica convencional, especialmente quando os casamentos arranjados à pressa pelo Duque no fim parecem prosseguir mais do que alterar a sua tendência para o seu reconhecido oportunismo político e sexual. 